\title{
COXIELLA BURNETII ANTIBODY DYNAMICS IN HEIFERS BORN TO VACCINATED VERSUS NON-VACCINATED DAMS IN A CHRONICALLY INFECTED DAIRY HERD
}

\author{
Joan TUTUSAUS, Irina GARCIA-ISPIERTO* and Fernando LÓPEZ-GATIUS \\ Agrotechnical Centre and Department of Animal Production, University of Lleida, \\ Av. Alcalde Rovira Roure 191, 25198 Lleida, Spain
}

(Received 9 May 2015; accepted 22 June 2015)

\begin{abstract}
This study was designed to compare Coxiella burnetii antibody dynamics in heifers born to vaccinated or non-vaccinated dams in a single high-producing dairy herd chronically infected with the bacterium. Antibody dynamics were examined from birth to the postpartum period in replacement heifers $(n=14)$ born to non-vaccinated dams $(\mathrm{n}=7)$ or to dams that had been vaccinated on gestation days 171-177 $(\mathrm{n}=7)$ and 192-198. Samples of blood, milk, faeces, vaginal fluid, colostrum and cotyledons (the latter two only at parturition) were obtained in the dams over the period from gestation days 171-177 to postpartum days 91-97. Blood samples were used to detect antibodies against $C$. burnetii and remaining samples for PCR identification of the bacterium. In their calves/heifers, blood samples for antibody determinations were collected from birth to postpartum at the time points $1-7$ and 22-28 days and 3, 6 and 12 months of age; 90-96 and 210-216 days of gestation; and 22-28 days postpartum. All calves were born seronegative for $C$. burnetii. Irrespective of the shedding status of their mothers ( 7 were $C$. burnetii shedders), seroconversion occurred after colostrum intake in all calves born to seropositive cows $(n=9)$ and in two of three vaccinated seronegative dams. Thereafter antibody titres gradually declined and by 6 months of age all calves were seronegative. Seronegativity persisted until their first postpartum period. These findings indicate that cows vaccinated during advanced pregnancy transfer immunity to their calves via the colostrum. Maternal C. burnetii antibodies in calves persisted for three months in calves born both to seronegative vaccinated and seropositive dams.
\end{abstract}

Key words: Bovine reproduction, serology, Q fever, cattle

Q fever is a worldwide distributed re-emerging zoonosis caused by Coxiella burnetii, an intracellular Gram-negative bacillus (McCaul and Willams, 1981; Maurin and Raoult, 1999). Ruminants are the main source of infection for humans (Maurin and Raoult, 1999; Arricau-Bouvery and Rodolakis, 2005). Although the clinical implications of this disease in humans and small ruminants seem clear, in cattle the issue continues to generate controversy (Ruiz-Fons et al.,

*Corresponding author; E-mail: irinag@prodan.udl.cat; Phone: 0034 (973) 702-563 
2010; Agerholm, 2013; Garcia-Ispierto et al., 2014). Some authors have linked the presence of anti-C. burnetii antibodies to placenta retention, abortion or infertility (Krauss et al., 1987; To et al., 1995, 1998; Hässig and Lubsen, 1998). Others have noted no negative impacts of $C$. burnetii seropositivity in dairy cattle (Lange et al., 1992; Nielsen et al., 2011; Paul et al., 2012; Muskens et al., 2012), while some even argue that seropositivity improves fertility and helps maintain pregnancy in dairy cattle (López-Gatius et al., 2012).

The phase I vaccine seems to be the most protective measure against $C$. burnetii infection. In dairy cattle, vaccination has been noted to reduce shedding of the bacterium only in seronegative non-pregnant animals (Guatteo et al., 2008). When used in infected animals during the peri-insemination period, vaccination did not prevent $C$. burnetii shedding (Guatteo et al., 2008; Rousset et al., 2009). However, when administered during the dry-off period, while the vaccine did not reduce shedding (Tutusaus et al., 2014), it was able to improve the subsequent fertility of the herd (López-Helguera et al., 2013; Garcia-Ispierto et al., 2015).

Several studies have shown that $C$. burnetii seropositivity increases with parity (McCaughey et al., 2010; Böttcher et al., 2011; Paul et al., 2012; Tutusaus et al., 2013) and antibody levels remain stable for long periods (Guatteo et al., 2007; Garcia-Ispierto et al., 2011; Nogareda et al., 2012). However, most likely because of the difficulty in detecting infection at the farm level (Garcia-Ispierto et al., 2013), the pathogenesis of the disease is poorly understood. In a recent study (Tutusaus et al., 2013), all calves born to seropositive animals tested seronegative until colostrum intake. However, to the best of our knowledge no study has examined whether colostrum antibodies persist in calves or tried to determine the exact time when calves or heifers become infected or undergo seroconversion. For farms rearing their own heifers, this type of information is essential to control C. burnetii infection at the herd level. The present study was designed to explore $C$. burnetii antibody dynamics from birth to the first postpartum period in replacement heifers born to vaccinated and non-vaccinated dams in a chronically infected high-producing dairy herd.

\section{Materials and methods}

\section{Cattle and herd management}

The study was performed from March 2011 to June 2014 in a commercial Holstein-Friesian dairy herd (NE Spain) including 625 lactating animals. Cows were milked three times daily. Mean annual milk production was $11,343 \mathrm{~kg}$ and the culling rate for the study period was $29 \%$. The mean calf mortality rate was $9 \%$ and the mean conception rate (number of artificial inseminations per positive pregnancy diagnosis) was 33\%. The cows calved all year round and were fed 
complete rations in line with the National Research Council recommendations (2001). All cows were bred by artificial insemination (AI).

All animals were tuberculosis and brucellosis free, as indicated by yearly tests from 1985 to 2014. Vaccination programmes for the prevention of bovine viral diarrhoea (BVD) and infectious bovine rhinotracheitis (IBR) included the use of modified live vaccines for animals 6-8 months old. Pregnant animals were given killed vaccines during the 7 th month of each gestation period. Parous cows that were not pregnant on day 150 postpartum received a further killed vaccine.

In yearly tests from 2009 to 2014, C. burnetii DNA was detected by polymerase chain reaction (PCR) in the bulk tank milk (BTM) indicating an excretion rate higher than $10^{3}$ bacteria/mL and ELISA tests indicated a seroprevalence higher than 30\% (Garcia-Ispierto et al., 2010, 2011; López-Gatius et al., 2012; Nogareda et al., 2012; Tutusaus et al., 2014). The herd was therefore considered to be persistently infected with $C$. burnetii.

Efforts were made to reduce variation in the general health status of the animals so that serological changes could be attributed to factors other than the clinical condition of the heifers during the study. The final data examined were derived from 14 replacement heifers (from birth to their first parturition period) and their mothers.

\section{Experimental design}

At the study outset, 14 pregnant cows were randomly assigned to a control (non-vaccinated) $(n=7)$ or vaccine $(n=7)$ group. Cows in the vaccine group received two subcutaneous injections three weeks apart of inactivated phase I vaccine (Coxevac ${ }^{\mathbb{B}}$, CEVA Santé Animale, Libourne, France) on days 171-177 and days 192-198 of gestation. Each 4-mL vaccine dose contained purified corpuscular phase I C. burnetii antigens $(100 \mu \mathrm{g} / \mathrm{mL})$ inactivated with formaldehyde. On gestation days 171-177, at parturition and on postpartum days 1-7, 8-14, 15-21, 22-28, 29-35 and 91-97, blood, milk, faeces, vaginal fluid, and colostrum and cotyledons (only at parturition) were collected from the cows. Blood samples in their calves were collected at birth before colostrum intake and at the ages 1-7 and 22-28 days and 3, 6 and 12 months. After pregnancy diagnosis in each heifer, blood samples were also collected at 90-96 and 210-216 days of gestation and at 22-28 days post partum.

\section{Sampling procedures}

Blood samples were collected from the coccygeal vein in dams and the jugular vein in calves (from birth to 3 months old) into heparinised vacuum tubes (BD Vacutainer ${ }^{\mathrm{TM}}$, Becton-Dickinson and Company, Plymouth, UK). Tubes were centrifuged $(10 \mathrm{~min}, 1600 \times \mathrm{g})$ within $30 \mathrm{~min}$ after collection and the plasma was stored at $-20{ }^{\circ} \mathrm{C}$ until analysis. 
Milk and colostrum samples were collected in a plastic sterile container for PCR. To minimise the risk of contamination during the collection process, teats were washed in clean water and then each teat end was scrubbed with antiseptic teat wipes. Finally, milk and colostrum were collected from the four teats after elimination of the first stream. Samples were frozen at $-20{ }^{\circ} \mathrm{C}$ prior to analysis.

After disinfection of the vulva with iodine solution, a vaginal swab was obtained and stored at $-20^{\circ} \mathrm{C}$. Faecal samples were collected into sterile containers using a rectal examination glove.

Placenta specimens were obtained immediately after parturition. After washing the perineum with iodine solution, three cotyledons were excised using rectal palpation gloves. All specimens were stored after their collection at $-20{ }^{\circ} \mathrm{C}$ until PCR analysis.

\section{Laboratory tests}

Coxiella burnetii antibodies. A commercial indirect ELISA, CoxLS kit (LSIVET RUMINANT Milk/Serum Q FEVER; Laboratoire Service International, Lissieu, France) was used to determine antibodies to $C$. burnetii according to the manufacturer's instructions. After validation studies (data not shown) we used plasma samples instead of blood serum. A cocktail of both antigen phases (I and II) was used in this assay to detect total anti-C. burnetii immunoglobulins $\mathrm{G}$ (IgG) (Guatteo et al., 2008). The results were expressed as S/P ratios. A sample was scored positive when the $\mathrm{S} / \mathrm{P}$ ratio $>0.4$. The sensitivity and specificity of this ELISA test have been estimated to be $85 \%$ and $95 \%$, respectively (Courcoul et al., 2010).

Polymerase chain reaction. Coxiella burnetii was PCR-detected in the cotyledons and colostrum, milk, faeces and vaginal fluid samples using a commercial kit targeting the repeat transposon-like region of $C$. burnetii (LSI Taqvet Coxiella burnetii ${ }^{\circledR}$; Laboratoire Service International) according to the manufacturer's instructions. The positive control used was a solution containing $10^{5} \mathrm{C}$. burnetii/mL (provided by UR INRA IASP, Nouzilly, France). The negative control sample used was DNase Rnase-free water. DNA was extracted from the different samples using the QIAmp DNA minikit ${ }^{\circledR}$ (Qiagen S.A., Courtaboeuf Cedex, France) according to the manufacturer's instructions. For the milk or vaginal mucus samples, DNA was extracted directly from $200 \mu \mathrm{L}$ of raw milk or $200 \mu \mathrm{L}$ of the obtained mucous dilution. For the faeces samples, $1 \mathrm{~g}$ of the original sample was weighed and mixed by vortexing for $30 \mathrm{~s}$ with $4 \mathrm{~mL}$ of DNase RNase-free water and $400 \mu \mathrm{L}$ then collected. Finally, samples were centrifuged at $6000 \times g$ for $1 \mathrm{~min}$ and $200 \mu \mathrm{L}$ of the supernatants used for DNA extraction. For the cotyledon samples, DNA was extracted from $25 \mathrm{mg}$ of tissue cut into small pieces and placed in a $1.5-\mathrm{mL}$ microcentrifuge tube. 


\section{Data collection and analysis}

Dams. The following data were recorded for each cow: parity (primiparous versus multiparous cows), treatment group (control vs. vaccination), and $C$. burnetii seropositivity and shedding status on gestation days 171-177, at parturition and on postpartum days $1-7,8-14,15-21,22-28,29-35$ and 91-97. When one or more PCR-positive samples (milk, faeces, vaginal fluid, colostrum or placenta) were recorded on one or more sampling days, the cow was recorded as shedding-positive.

Replacement heifers. Coxiella burnetii serostatus in each calf/heifer was determined at birth before colostrum intake and at the ages of 1-7 and 22-28 days, at 3, 6 and 12 months, at 90-96 and 210-216 days of gestation and at 2228 days post partum.

For each calf/heifer, $C$. burnetii serostatus at day 1-7 of age was compared with the serostatus ( $C$. burnetii seronegative vs. seropositive) of its dam according to the mother's shedding status, parity and treatment group using a $\chi^{2}$ test. The effects of these variables on the $\mathrm{S} / \mathrm{P}$ ratio recorded in calves/heifers were assessed by GLM repeated measures analysis of variance. All statistical tests were performed using the SPSS package version 18.0 (SPSS Inc., Chicago, IL, USA). Significance was set at $\mathrm{P}<0.05$.

\section{Results}

Dams

The mean $( \pm \mathrm{SD})$ lactation number was $1.93 \pm 0.73$ and ranged from 1 to 4. At the study outset, there were $5(71.4 \%)$ and $4(57.1 \%)$ C. burnetii-seropositive animals in the control and vaccination groups, respectively. Bacterial shedding (at least at one time point) was detected in $7(50 \%)$ dams, of which $5(71.4 \%)$ were $C$. burnetii seropositive. Seroconversion was not observed in any of the seronegative dams in the control group, whilst seroconversion was recorded in two of the three $(66.7 \%)$ seronegative dams in the vaccination group. Seropositive cows maintained their seropositivity throughout the study period.

\section{Replacement heifers}

Data regarding the serostatus of each calf according to the characteristics of its mother (serostatus, shedding status, parity, treatment group) are provided in Table 1. Upon birth, all the calves were seronegative for $C$. burnetii. In 11 of the 14 calves $(78.6 \%)$, seroconversion was observed after colostrum intake, 9 of which had been born to seropositive dams (non-vaccinated and vaccinated) and two to seronegative vaccinated dams. The remaining three seronegative calves were born to one seronegative vaccinated dam and to two seronegative control dams, respectively. Two (18.2\%) and three $(27.3 \%)$ of the 11 initially seroposi- 
tive calves became seronegative at 22-28 days and 3 months of age, respectively. The remaining six seropositive calves became seronegative at 6 months of age. Seronegativity remained stable from six months to the end of the study period (Fig. 1). The $\chi^{2}$ test revealed a higher C. burnetii seropositivity rate on day $1-7$ of age in calves born to seropositive dams than seronegative dams $(81.8 \%$ vs. $18.2 \%$, respectively, $\mathrm{P}=0.027$ ). No other significant differences were detected.

\section{Table 1}

Coxiella burnetii serostatus of replacement calves after colostrum intake (at 1-7 days of age) according to the characteristics of their mothers

\begin{tabular}{lllcc}
\hline Dam factor & \multicolumn{2}{c}{ Class } & Seronegative $(\mathrm{n}=3)$ & Seropositive $(\mathrm{n}=11)$ \\
\hline \multirow{2}{*}{ Serostatus } & Seronegative & $(\mathrm{n}=5)$ & 3 & 2 \\
& Seropositive & $(\mathrm{n}=9)$ & 0 & 9 \\
\hline \multirow{2}{*}{ Shedding status } & Shedder & $(\mathrm{n}=7)$ & 1 & 6 \\
& Non-shedder & $(\mathrm{n}=7)$ & 2 & 5 \\
\hline \multirow{2}{*}{ Treatment } & Vaccinated & $(\mathrm{n}=7)$ & 1 & 6 \\
& Non-vaccinated & $(\mathrm{n}=7)$ & 2 & 5 \\
\hline Parity & Primiparous & $(\mathrm{n}=3)$ & 1 & 2 \\
& Multiparous & $(\mathrm{n}=11)$ & 2 & 9
\end{tabular}

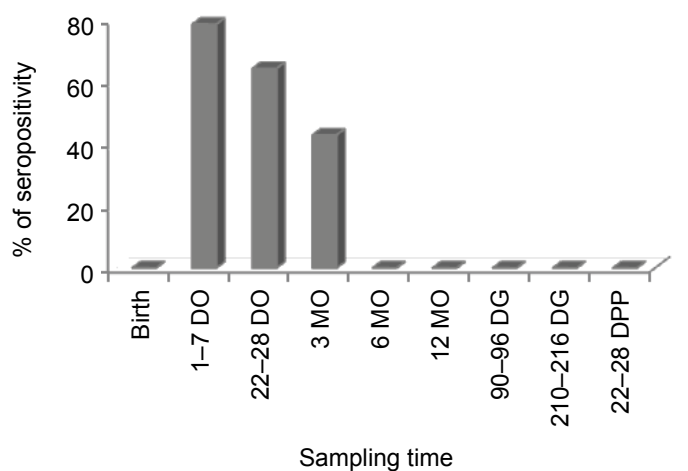

Fig. 1. Evolution of Coxiella burnetii seropositivity of replacement heifers from birth (before colostrum intake) to 22-28 days after their first parturition. Sampling time: Days old (DO), Months old (MO), Days of gestation (DG), Days postpartum (DPP)

The mean age at pregnancy in the heifers was $15.1 \pm 0.9$ months, ranging from 14 to 17 months. No associations were identified throughout the study period between heifer seropositivity and $C$. burnetii shedding status, parity or vaccination in the corresponding dams by GLM repeated measures ANOVA. Calves born to seropositive dams showed significantly higher anti-C. burnetii antibody 
levels from 1-7 days to 3 months of age compared with those born to seronegative dams (between subject effects, $\mathrm{P}=0.026$ ) (Fig. 2).

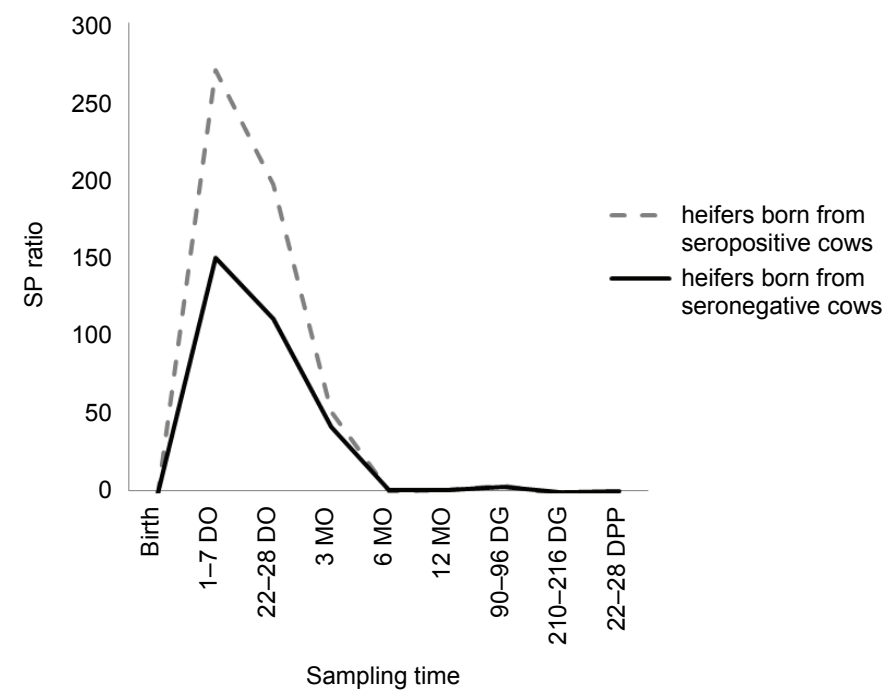

Fig. 2. Mean Coxiella burnetii $\mathrm{S} / \mathrm{P}$ ratio $(\mathrm{S} / \mathrm{P} \times 100)$ recorded for replacement heifers born from seropositive $(\mathrm{n}=9)$ and seronegative vaccinated $(\mathrm{n}=2)$ cows throughout the study period (between subject effects, $\mathrm{P}=0.026$ ). Sampling time: Days old (DO), Months old (MO), Days of gestation (DG), Days postpartum (DPP)

\section{Discussion}

To the best of our knowledge, this is the first study to address C. burnetii antibody dynamics from birth to parturition in replacement heifers. Seroconversion was detected after colostrum intake in all calves born to seropositive dams and in calves born to two of three vaccinated seronegative dams. By 6 months of age, all calves were seronegative and remained so until their first postpartum period.

Coxiella burnetii antibodies initially transferred to calves via the mothers' colostrum gradually declined over time. Hence, by 6 months of age all the animals were seronegative. Similar maternal antibody dynamics have been reported for Schmallenberg virus (Elbers et al., 2014) as well as IBR and BVD (Menanteau-Horta et al., 1985). This type of information is essential for the design of an effective vaccination schedule since colostral antibodies may interfere with vaccination (Menanteau-Horta et al., 1985; Vitour et al., 2011; Downey et al., 2013). The phase I C. burnetii vaccine is usually given to nulliparous heifers of 12 months or older (Taurel et al., 2014). The present findings suggest that vaccination in heifers could be brought forward to six months of age. 
In agreement with the results of our previous work (Tutusaus et al., 2013), all newborn calves were seronegative before colostrum intake, suggesting a lack of vertical transmission. In two of three vaccinated cows, antibodies were transferred via the colostrum to their calves. This indicates passive immunisation of calves born to vaccinated dams as described in other infectious diseases affecting cattle such as bovine rotavirus, bovine coronavirus, bovine parvovirus, Escherichia coli and Cryptosporidium parvum (Kohara et al., 1997; Perryman et al., 1999; Burton et al., 2011). Thus, vaccinating cows during the dry-off period seems to be a good strategy to control Q fever on dairy farms raising their own replacement animals. However, according to the present data, in one of three seronegative vaccinated dams, antibodies were not transferred to the newborn calf via the colostrum. There are several descriptions in the literature of multiparous shedding seronegative cows that do not raise a humoral response against $C$. burnetii (Guatteo et al., 2007; Rousset et al., 2009; Garcia-Ispierto et al., 2011; Hansen et al., 2011; Nogareda et al., 2012). This lack of response is likely attributable to genetic resistance to infection or the immunotolerance of these animals.

No links were detected between calf $C$. burnetii seropositivity and dam factors such as parity, Coxiella-shedding status and vaccination status. In contrast, several studies have identified parity (McCaughey et al., 2010; Böttcher et al., 2011; Paul et al., 2012; Tutusaus et al., 2013), C. burnetii shedding (Guatteo et al., 2007; Courcoul et al., 2010) and vaccination against the bacterium (Tutusaus et al., 2014) as maternal factors related to the C. burnetii seropositivity of their offspring. The lack of effects of these factors observed here may be explained by our small sample size.

In conclusion, the results of this study indicate that cows vaccinated at an advanced stage of pregnancy transferred immunity towards $C$. burnetii to their calves via the colostrum. Maternal $C$. burnetii antibodies persisted for three months in calves born to both seronegative vaccinated and seropositive dams.

\section{Acknowledgements}

The authors thank the owners and staff of the farm for their co-operation, Beatriz Serrano for technical help and Ana Burton for assistance with the English translation. Joan Tutusaus was supported by a grant from the University of Lleida, Spain.

\section{References}

Agerholm, J. S. (2013): Coxiella burnetii associated reproductive disorders in domestic animals: a critical review. Acta Vet. Scand. 55, 13.

Arricau-Bouvery, N. and Rodolakis, A. (2005): Is Q fever an emerging or reemerging zoonosis? Vet. Res. 36, 327-349. 
Böttcher, J., Vossen, A., Janowetz, B., Alex, M., Gangl, A., Randt, A. and Meier, N. (2011): Insights into the dynamics of endemic Coxiella burnetii infection in cattle by application of phase-specific ELISAs in an infected dairy herd. Vet. Microbiol. 151, 291-300.

Burton, A. J., Nydam, D. V., Jones, G., Zambriski, J. A., Linden, T. C., Cox, G., Davis, R., Brown, A. and Bowman, D. D. (2011): Antibody responses following administration of a Cryptosporidium parvum $\mathrm{rCP} 15 / 60$ vaccine to pregnant cattle. Vet. Parasitol. 175, 178-181.

Courcoul, A., Vergu, E., Denis, J. B. and Beaudeau, F. (2010): Spread of Q fever within dairy cattle herds: key parameters inferred using a Bayesian approach. Proc. Biol. Sci. 22, 2857-2865.

Downey, E. D., Tait, R. G., Mayes, M. S., Park, C. A., Ridpath, J. F., Garrick, D. J. and Reecy, J. M. (2013): An evaluation of circulating bovine viral diarrhea virus type 2 maternal antibody level and response to vaccination in Angus calves. J. Anim. Sci. 91, 4440-4450.

Elbers, A. R., Stockhofe, N. and van der Poel, W. H. (2014): Schmallenberg virus antibodies in adult cows and maternal antibodies in calves. Emerg. Infect. Dis. 20, 901-902.

Garcia-Ispierto, I., Almería, S. and López-Gatius, F. (2011): Coxiella burnetii seropositivity is highly stable throughout gestation in lactating high-producing dairy cows. Reprod. Domest. Anim. 46, 1067-1072.

Garcia-Ispierto, I., López-Helguera, I., Tutusaus, J., Mur-Novales, R. and López-Gatius, F. (2015): Effects of long-term vaccination against Coxiella burnetii on the fertility of high-producing dairy cows. Acta Vet. Hung. 63, 223-233.

Garcia-Ispierto, I., López-Helguera, I., Tutusaus, J., Serrano, B., Monleón, E., Badiola, J. J. and López-Gatius, F. (2013): Coxiella burnetii shedding during the peripartum period and subsequent fertility in dairy cattle. Reprod. Domest. Anim. 48, 441-446.

Garcia-Ispierto, I., Nogareda, C., Yániz, J. L., Almería, S., Martínez-Bello, D., de Sousa, N. M., Beckers, J. F. and López-Gatius, F. (2010): Neospora caninum and Coxiella burnetii seropositivity are related to endocrine pattern changes during gestation in lactating dairy cows. Theriogenology 74, 212-220.

Garcia-Ispierto, I., Tutusaus, J. and López-Gatius, F. (2014): Does Coxiella burnetii affect reproduction in cattle? A clinical update. Reprod. Domest. Anim. 49, 529-535.

Guatteo, R., Beaudeau, F., Joly, A. and Seegers, H. (2007): Coxiella burnetii shedding by dairy cows. Vet. Res. 38, 849-860.

Guatteo, R., Seegers, H., Joly, A. and Beaudeau, F. (2008): Prevention of Coxiella burnetii shedding in infected dairy herds using a phase I C. burnetii inactivated vaccine. Vaccine 26, $4320-4328$.

Hansen, M. S., Rodolakis, A., Cochonneau, D., Agger, J. F., Christoffersen, A. B., Jensen, T. K. and Agerholm, J. S. (2011): Coxiella burnetii associated placental lesions and infection level in parturient cows. Vet. J. 190, 135-139.

Hässig, M. and Lubsen, J. (1998): Relationship between abortions and seroprevalences to selected infectious agents in dairy cows. Zbl. Vet. Med. B 45, 435-441.

Kohara, J., Hirai, T., Mori, K., Ishizaki, H. and Tsunemitsu, H. (1997): Enhancement of passive immunity with maternal vaccine against newborn calf diarrhea. J. Vet. Med. Sci. 59, $1023-1025$.

Krauss, H., Schmeer, N. and Schiefer, H. G. (1987): Epidemiology and significance of Q fever in the Federal Republic of Germany. Zbl. Bakteriol. Mikrobiol. Hyg. A 267, 42-50.

Lange, S., Sollner, H., Dittmar, H., Hofmann, J. and Lange, A. (1992): Q fever antibody titer follow up study in cattle with special reference to pregnancy. Berl. Munch. Tierarztl. Wochenschr. 105, 260-263.

López-Gatius, F., Almería, S. and Garcia-Ispierto, I. (2012): Serological screening for Coxiella burnetii infection and related reproductive performance in high producing dairy cows. Res. Vet. Sci. 93, 67-73.

López-Helguera, I., López-Gatius, F., Tutusaus, J. and Garcia-Ispierto, I. (2013): Reproductive performance of high producing lactating cows in Coxiella-infected herds following vaccination with phase-1 Coxiella burnetii vaccine during advanced pregnancy. Vaccine 31, 3046-3050. 
Maurin, M. and Raoult, D. (1999): Q fever. Clin. Microbiol. Rev. 12, 518-553.

Menanteau-Horta, A. M., Ames, T. R., Johnson, D. W. and Meiske, J. C. (1985): Effect of maternal antibody upon vaccination with infectious bovine rhinotracheitis and bovine virus diarrhea vaccines. Can. J. Comp. Med. 49, 10-14.

McCaughey, C., Murray, L. J., McKenna, J. P., Menzies, F. D., McCullough, S. J., O’Neill, H. J., Wyatt, D. E., Cardwell, C. R. and Coyle, P. V. (2010): Coxiella burnetii (Q fever) seroprevalence in cattle. Epidemiol. Infect. 138, 21-27.

McCaul, T. F. and Williams, J. C. (1981): Developmental cycle of Coxiella burnetii: structure and morphogenesis of vegetative and sporogenic differentiations. J. Bacteriol. 147, 1063-1076.

Muskens, J., Wouda, W., von Bannisseht-Wijsmuller, T. and van Maanen, C. (2012): Prevalence of Coxiella burnetii infections in aborted fetuses and stillborn calves. Vet. Rec. 170, 260.

National Research Council (2001): Nutrient Requirements of Dairy Cattle. Seventh revised edition. National Academy Press, Washington D.C., USA.

Nielsen, K. T., Nielsen, S. S., Agger, J. F., Christoffersen, A. B. and Agerholm, J. S. (2011): Association between antibodies to Coxiella burnetii in bulk tank milk and perinatal mortality of Danish dairy calves. Acta Vet. Scand. 53, 64.

Nogareda, C., Almería, S., Serrano, B., Garcia-Ispierto, I. and López-Gatius, F. (2012): Dynamics of Coxiella burnetii antibodies and seroconversion in a dairy cow herd with endemic infection and excreting high numbers of the bacterium in the bulk tank milk. Res. Vet. Sci. 93, $1211-1212$.

Paul, S., Agger, J. F., Markussen, B., Christoffersen, A. B. and Jørgen, S. (2012): Factors associated with Coxiella burnetii antibody positivity in Danish dairy cows. Prev. Vet. Med. 107, $57-64$.

Perryman, L. E., Kapil, S. J., Jones, M. L. and Hunt, E. L. (1999): Protection of calves against cryptosporidiosis with immune bovine colostrum induced by a Cryptosporidium parvum recombinant protein. Vaccine 23, 2142-2149.

Rousset, E., Berri, M., Durand, B., Dufour, P., Prigent, M., Delcroix, T., Touratier, A. and Rodolakis, A. (2009): Coxiella burnetii shedding routes and antibody response after outbreaks of Q fever-induced abortion in dairy goat herds. Appl. Environ. Microbiol. 75, 428-433.

Ruiz-Fons, F., Astobiza, I., Barandika, J. F., Hurtado, A., Atxaerandio, R., Juste, R. A. and GarcíaPérez, A. L. (2010): Seroepidemiological study of Q fever in domestic ruminants in semiextensive grazing systems. BMC Vet. Res. 6, 3 .

Taurel, A., Guatteo, R., Lehebel, A., Joly, A. and Beaudeau, F. (2014): Vaccination using phase I vaccine is effective to control Coxiella burnetii shedding in infected dairy cattle herds. Comp. Immunol. Microbiol. Infect. Dis. 37, 1-9.

To, H., Htwe, K. K., Kako, N., Kim, H. J., Yamaguchi, T., Fukushi, H. and Hirai, K. (1998): Prevalence of Coxiella burnetii infection in dairy cattle with reproductive disorders. J. Vet. Med. Sci. 60, 859-861.

To, H., Htwe, K. K., Yamasaki, N., Zhang, G. Q., Ogawa, M., Yamaguchi, T., Fukushi, H. and Hirai, K. (1995): Isolation of Coxiella burnetii from dairy cattle and ticks, and some characteristics of the isolates in Japan. Vet. Res. 36, 327-349.

Tutusaus, J., López-Gatius, F., Almería, S., Serrano, B., Monleón, E., Badiola, J. J. and GarciaIspierto, I. (2013): No detectable precolostral antibody response in calves born from cows with cotyledons positive for Coxiella burnetii by quantitative PCR. Acta Vet. Hung. 61, $432-441$.

Tutusaus, J., López-Gatius, F., Serrano, B., Monleón, E., Badiola, J. J. and Garcia-Ispierto, I. (2014): Serological and shedding patterns after Coxiella burnetii vaccination in the third gestation trimester in dairy cows. Acta Vet. Hung. 62, 145-154.

Vitour, D., Guillotin, J., Sailleau, C., Viarouge, C., Desprat, A., Wolff, F., Belbis, G., Durand, B., Bakkali-Kassimi, L., Breard, E., Zientara, S. and Zanella, G. (2011): Colostral antibody induced interference of inactivated bluetongue serotype-8 vaccines in calves. Vet. Res. 42, 18. 